\title{
Perioperative Systemic Treatment for Muscle-Invasive Bladder Cancer: Current Evidence and Future Perspectives
}

\author{
In-Ho Kim ${ }^{1}$ and Hyo-Jin Lee ${ }^{2, *(1)}$ \\ 1 Department of Internal Medicine, Division of Medical Oncology, Seoul St. Mary's Hospital, The Catholic \\ University of Korea College of Medicine, Seoul 06591, Korea; ihkmd@catholic.ac.kr \\ 2 Department of Internal Medicine, Chungnam National University School of Medicine, Daejeon 35015, Korea \\ * Correspondence: cymed@cnuh.co.kr; Tel.: +82-42-280-8369; Fax: +82-42-257-5753
}

Citation: Kim, I.-H.; Lee, H.-J. Perioperative Systemic Treatment for Muscle-Invasive Bladder Cancer: Current Evidence and Future Perspectives. Int. J. Mol. Sci. 2021, 22, 7201. https://doi.org/10.3390/ ijms 22137201

Academic Editor: Georg C. Hutterer

Received: 29 May 2021

Accepted: 30 June 2021

Published: 4 July 2021

Publisher's Note: MDPI stays neutral with regard to jurisdictional claims in published maps and institutional affiliations.

Copyright: (c) 2021 by the authors. Licensee MDPI, Basel, Switzerland. This article is an open access article distributed under the terms and conditions of the Creative Commons Attribution (CC BY) license (https:// creativecommons.org/licenses/by/ $4.0 /)$.

\begin{abstract}
Radical cystectomy is the primary treatment for muscle-invasive bladder cancer; however, approximately $50 \%$ of patients develop metastatic disease within 2 years of diagnosis, which results in dismal prognosis. Therefore, systemic treatment is important to improve the prognosis of muscle-invasive bladder cancer. Currently, several guidelines recommend cisplatin-based neoadjuvant chemotherapy before radical cystectomy, and adjuvant chemotherapy is recommended in patients who have not received neoadjuvant chemotherapy. Immune checkpoint inhibitors have recently become the standard treatment option for metastatic urothelial carcinoma. Owing to their clinical benefits, several immune checkpoint inhibitors, with or without other agents (including other immunotherapy, cytotoxic chemotherapy, and emerging agents such as antibody drug conjugates), are being extensively investigated in perioperative settings. Several studies for perioperative immunotherapy have shown that immune checkpoint inhibitors have promising efficacy with relatively low toxicity, and have explored the predictive molecular biomarkers. Herein, we review the current evidence and discuss the future perspectives of perioperative systemic treatment for muscle-invasive bladder cancer.
\end{abstract}

Keywords: bladder cancer; immunotherapy; perioperative systemic treatment

\section{Introduction}

Bladder cancer is the 12th most common malignancy worldwide, causing approximately 200,000 deaths annually [1]. Muscle-invasive bladder cancer (MIBC) represents approximately $20 \%$ of newly diagnosed bladder cancer cases [2]. Currently, radical cystectomy (RC) with pelvic lymph node dissection is the primary treatment for MIBC; however, the disease tends to recur within two years in approximately $50 \%$ of patients [3]. Therefore, perioperative systemic treatment is important to improve MIBC prognosis. Current international guidelines recommend cisplatin-based neoadjuvant chemotherapy (NAC) followed by RC in patients with MIBC; adjuvant chemotherapy is also an option for select patients [4,5]. Recently, owing to the success of immunotherapy in treating metastatic disease, a perioperative immunotherapy-based treatment strategy for MIBC is being extensively investigated. Herein, we review the current evidence, and discuss the future perspectives of perioperative systemic treatment for MIBC.

\section{Data Acquisition}

A literature survey for current data on perioperative systemic therapy was conducted using the PubMed and ClinicalTrials.gov databases. The following combination of $\mathrm{MeSH}$ terms was used in the data searching process: "urothelial carcinoma", "transitional cell carcinoma", or "bladder cancer"; and "neoadjuvant", "adjuvant", "preoperative", "postoperative", or "perioperative". Prospective/retrospective studies, systematic reviews, and meta-analyses were included. As perioperative immunotherapy-based treatment is a rapidly changing field, we also examined abstracts from major oncology conferences 
between January 2010 and March 2021. Moreover, we included the available data from ongoing clinical trials on perioperative immunotherapy.

\section{Perioperative Chemotherapy in MIBC}

Currently, cisplatin-based NAC followed by RC is the standard of care for MIBC. The National Comprehensive Cancer Network (NCCN) guidelines recommend cisplatin-based NAC as a category 1 treatment for patients with clinical T2-4a (cT2-4a) or N1 who are fit for cisplatin treatment [5]; the European Association of Urology (EAU) guidelines also strongly recommend cisplatin-based NAC for CT2-T4a disease [4]. Several randomized phase 3 studies have shown that NAC has a clinical benefit in MIBC [6-8]. In 2003, SWOG/The Eastern Cooperative Oncology Group and Cancer and Leukemia Group B reported the results of neoadjuvant methotrexate, vinblastine, doxorubicin, and cisplatin (MVAC) in 317 patients with cT2-4aN0M0 bladder cancer. The primary endpoint of the study was overall survival (OS). The median OS and 5-year survival rates were 77 months and 57\%, respectively, in the NAC group vs. 46 months and $43 \%$, respectively, in the surgery-alone group [6]. A Nordic collaborative group performed a combined analysis of two separate trials that were similar in design and had the same source population [7]; this study showed that NAC showed an $8 \%$ improvement in the 5 -year OS rate $56 \%$ in the NAC group vs. $48 \%$ in the control group), and was associated with a $20 \%$ reduction in the relative probability of death. The BA06 30894 trial was an international, multicenter study that compared local radical treatment alone with neoadjuvant cisplatin, methotrexate, and vinblastine (CMV), followed by local radical treatment. The first analysis of this study showed a nonsignificant $15 \%$ reduction in the risk of death associated with neoadjuvant CMV [8]. In 2011, the updated analysis of this study, with a median follow-up of eight years, showed a statistically significant $16 \%$ reduction in the risk of death associated with neoadjuvant CMV, compared with the control group. Furthermore, the 10-year survival increased from $30 \%$ to $36 \%$ after neoadjuvant CMV, compared with the control group [9]. Three meta-analyses were performed to evaluate the clinical benefits of NAC; these studies confirmed that NAC led to an improvement in OS of approximately 5\% in MIBC [10-12]. A modified MVAC has been investigated in two small, single-arm phase 2 trials $[13,14]$. Choueiri et al. (NCT00808639) evaluated the efficacy and safety of neoadjuvant dose-dense MVAC (dd-MVAC) with pegfilgrastim support in 39 patients with MIBC (cT2-cT4N0-1M0) [13]. The primary endpoint was pathologic response $(\mathrm{PaR})$, defined by pathologic downstaging to $\leq$ pT1N0M0. This study showed that $49 \%$ of patients achieved PaR, with $10 \%$ showing grade 3 or higher treatment-related toxicities. Plimack et al. (NCT01031420) assessed the feasibility of neoadjuvant-accelerated MVAC with pegfilgrastim in 44 patients with MIBC (cT2-cT4N0-1M0) [14]. The primary endpoint was pathologic complete response (pT0, $\mathrm{pCR}$ ). This study revealed $38 \% \mathrm{pCR}$ rates and $52 \%$ downstaging to non-muscle-invasive disease. Most patients (82\%) experienced only grade 1-2 treatment-related toxicities. Combined gemcitabine and cisplatin (GC) treatment is also used in the neoadjuvant setting because of its similar OS and progression-free survival (PFS) and lower toxicity in metastatic disease compared with conventional MVAC [15]. Although GC has not been investigated in large-scale randomized prospective phase 3 trials, several retrospective and pooled analyses suggest that GC has a similar response in terms of pathologic downstaging to T0/1 [16-20]. The GETUG/AFU V05 VESPER trial (NCT01812369) is a randomized phase 3 controlled study comparing the efficacy of GC and dd-MVAC in a perioperative setting [21]. Among the 537 patients in the neoadjuvant group, pCR was observed in $36 \%$ of GC and $42 \%$ of dd-MVAC patients $(p=0.2)$; downstaging to organ-confined disease $(<y p T 3 p N 0)$ was achieved in $63 \%$ (GC) and 77\% (dd-MVAC) of patients, respectively $(p=0.001)$. Grade 3 or higher hematologic toxicities were observed in $52 \%$ of patients in the dd-MVAC group and $55 \%$ of patients in the GC group. Grade 3 or higher gastrointestinal toxicity $(p=0.003)$ and asthenia $(p<0.001)$ were more frequently observed in the dd-MVAC arm. As this was a preliminary report, the result of the PFS as the primary endpoint has not yet been reported. We have summarized the results of NAC trials in MIBC in Table 1. 
Table 1. Summary of trials for cisplatin-based neoadjuvant chemotherapy in muscle-invasive bladder cancer.

\begin{tabular}{|c|c|c|c|c|c|c|}
\hline & SWOG-8710 [6] & BA06 30894 [8] & $\begin{array}{l}\text { Choueiri et al. [13] } \\
\text { (NCT00808639) }\end{array}$ & $\begin{array}{l}\text { Plimack et al. [14] } \\
\text { (NCT01031420) }\end{array}$ & $\begin{array}{c}\text { Dash et al. } \\
\text { [18] }\end{array}$ & $\begin{array}{c}\text { MSK } \\
{[20]}\end{array}$ \\
\hline $\mathrm{N}$ & 317 & 976 & 39 & 40 & 42 & 154 \\
\hline Phase & 3 & 3 & 2 & 2 & $\mathrm{R}$ & $\mathrm{R}$ \\
\hline Regimen & MVAC & $\mathrm{CMV}$ & ddMVAC & aaMVAC & GC & GC \\
\hline Duration of NAC, weeks & 14 & NA & 8 & 6 & 12 & 12 \\
\hline $\begin{array}{l}\text { Median time to definitive } \\
\text { treatment after } \\
\text { randomization, weeks }\end{array}$ & 16 & NA & 14 & 9.7 & 19 & 17 \\
\hline Planned surgery rates, $\%$ & 82 & NA & 97 & 98 & NA & NA \\
\hline pCR (pT0N0) rates, $\%$ & 38 & NA & 26 & 38 & 26 & 21 \\
\hline $\begin{array}{c}\text { Downstaging }(<\mathrm{pT} 2) \text { to } \\
\text { non-muscle invasive } \\
\text { disease, } \%\end{array}$ & 44 & NA & 49 & 53 & 36 & 46 \\
\hline
\end{tabular}

R: retrospective; NA: not available.

The role of adjuvant chemotherapy (AC) in MIBC has been investigated in several studies, although few studies are available as a reference. The EORTC 30994 trial (NCT00028756) was the largest AC trial that compared adjuvant versus deferred cisplatin-based combination chemotherapy after RC in patients with pT3-pT4 or N+ M0 urothelial carcinoma (UC) [22]. A total of 284 patients were randomly assigned (1:1) to either immediate AC (four cycles of GC, high dose MVAC, or conventional MVAC) or six cycles of deferred chemotherapy at relapse. The primary endpoint was OS. Although this study showed that AC significantly prolonged disease-free survival (DFS) compared with deferred treatment, no significant improvement in OS was noted with AC. The failure of this trial may be attributed to poor trial design and an inappropriate primary endpoint, and detailed information and the response of salvage treatment were not obtained. This explains why the observed benefit in DFS does not translate into a benefit in OS. Other trials [23-26] were in favor of AC; the clinical impression of these trials is limited, as these trials either did not achieve the primary endpoint or did not have a significant clinical implication because of poor study design, incomplete patient accrual, or early termination. In 2013, an updated meta-analysis was performed including 945 patients in 9 randomized clinical trials [27]. This study showed evidence of an OS and DFS benefit in patients with MIBC receiving AC after RC. Currently, the NCCN and EAU guidelines [4,5] recommend $\mathrm{AC}$ in patients with MIBC who have not received NAC; however, NAC is preferred over AC as the perioperative treatment option. We have summarized the trials for $\mathrm{AC}$ in patients with MIBC in Table 2.

Table 2. Summary of trials for cisplatin-based adjuvant chemotherapy in muscle-invasive bladder cancer.

\begin{tabular}{|c|c|c|c|}
\hline & $\begin{array}{c}\text { EORTC 30994, } 2015 \text { [22] } \\
\text { (NCT00028756) }\end{array}$ & SOGUG, 2010 [24] & Cognetti et al., 2012 [23] \\
\hline $\mathrm{N}$ & 284 & 142 & 194 \\
\hline Phase & 3 & 3 & 3 \\
\hline Regimen & GC, high-dose MVAC, MVAC & PGC & GC \\
\hline DFS & $\begin{array}{c}\text { 5-year DFS rates: } 47.6 \%(\mathrm{AC}) \text { vs. } \\
31.8 \% \text { (control) }\end{array}$ & NA & $\begin{array}{c}\text { 5-year DFS rates: } 37.2 \%(\mathrm{AC}) \text { vs. } \\
42.3 \% \text { (control) }\end{array}$ \\
\hline OS & $\begin{array}{c}\text { 5-year OS rates: } 53.6 \%(\mathrm{AC}) \text { vs. } \\
47.7 \% \text { (control) }\end{array}$ & $\begin{array}{c}\text { 5-year OS rates: } 60 \%(\mathrm{AC}) \text { vs. } \\
31 \% \text { (control) }\end{array}$ & $\begin{array}{c}\text { 5-year OS rates: } 43.4 \%(\mathrm{AC}) \text { vs. } \\
53.7 \% \text { (control) }\end{array}$ \\
\hline
\end{tabular}




\section{Neoadjuvant Immunotherapy in MIBC}

Recently, immune checkpoint inhibitor (CPI) therapy has become the standard treatment option for metastatic urothelial carcinoma (mUC) [28-37] (Table 3). In 2016-2017, atezolizumab, avelumab durvalumab, nivolumab, and pembrolizumab were approved for use in mUC by the United States Food and Drug Administration (FDA). Owing to their clinical benefits in metastatic settings, several CPIs are being investigated in perioperative settings. Therefore, we have discussed the current evidence of perioperative CPIs, and have summarized the results from recent trials in this section (Table 4).

Table 3. Summary of trials for immune checkpoint inhibitors in advanced/metastatic urothelial carcinoma.

\begin{tabular}{|c|c|c|c|c|c|c|c|c|c|}
\hline Trial & Drug & $\begin{array}{c}\text { Treatment } \\
\text { Line }\end{array}$ & Number & Phase & $\begin{array}{l}\text { Primary } \\
\text { Endpoint }\end{array}$ & ORR, \% & $\begin{array}{l}\text { Median } \\
\text { OS, } \\
\text { Months }\end{array}$ & $\begin{array}{l}\text { Median } \\
\text { PFS, } \\
\text { Months }\end{array}$ & $\begin{array}{c}\text { Grade } \\
3-4 \\
\text { TRAE, \% }\end{array}$ \\
\hline $\begin{array}{l}\text { IMvigor } 210 \text { [35] } \\
\text { (NCT02108652) }\end{array}$ & Atezolizumab & 1 & 119 & 2 & ORR & 23 & 15.9 & 2.7 & 16 \\
\hline $\begin{array}{l}\text { IMvigor } 211 \text { [28] } \\
\text { (NCT02302807) }\end{array}$ & Atezolizumab & 3 & 467 & 3 & OS & 13 & 8.6 & 2.1 & 20 \\
\hline $\begin{array}{l}\text { JAVELIN Solid } \\
\text { Tumor [29] } \\
\text { (NCT01772004) }\end{array}$ & Avelumab & 2 & 249 & $1 b$ & DLT & 17 & 6.5 & 1.6 & 8 \\
\hline $\begin{array}{l}\text { Study } 1108 \text { [34] } \\
\text { (NCT01693562) }\end{array}$ & Durvalumab & 2 & 191 & $1 / 2$ & $\begin{array}{l}\text { Safety, } \\
\text { ORR }\end{array}$ & 18 & 18.2 & 1.5 & 7 \\
\hline $\begin{array}{c}\text { CheckMate } 275 \\
{[30,37]} \\
\text { (NCT02387996) }\end{array}$ & Nivolumab & 2 & 265 & 2 & ORR & 20 & 8.6 & 1.9 & 25 \\
\hline $\begin{array}{c}\text { KETNOTE-052 } \\
{[33,36]} \\
(\text { NCT0233542) }\end{array}$ & Pembrolizumab & 1 & 370 & 2 & ORR & 29 & 11.3 & 2.2 & 21 \\
\hline $\begin{array}{c}\text { KETNOTE-045 } \\
{[31,32]} \\
(\text { NCT02256436) }\end{array}$ & Pembrolizumab & 2 & 542 & 3 & OS, PFS & 21 & 10.1 & 2.1 & 15 \\
\hline
\end{tabular}

DLT: Dose limiting toxicity.

Table 4. Summary of current neoadjuvant trials for immunotherapy with or without other agents in MIBC.

\begin{tabular}{|c|c|c|c|c|c|}
\hline Trial & Agent & Phase & Population & $\begin{array}{l}\text { Cisplatin } \\
\text { Eligibility }\end{array}$ & $\begin{array}{c}\text { Upper-Tract } \\
\text { Disease } \\
\text { Included }\end{array}$ \\
\hline \multicolumn{6}{|l|}{ Signle-Agent therapy } \\
\hline NCT02662309 (ABACUS) & Atezolizumab & 2 & cT2-T4N0 & $\mathrm{N}$ & $\mathrm{N}$ \\
\hline NCT02451423 & Atezolizumab & 2 & cTa-T4N0 & $\mathrm{N}$ & $\mathrm{N}$ \\
\hline NCT03577132 & Atezolizumab & 2 & cT2-T4N0-1 & $\mathrm{Y}$ & $\mathrm{N}$ \\
\hline NCT03498196 (BL-AIR) & Avelumab & $1 / 2$ & cT2-T4aN0 & $\mathrm{N}$ & $\mathrm{N}$ \\
\hline NCT03406650 (SAKK 06/17) & Durvalumab & 2 & cT2-T4N0-1 & $\mathrm{Y}$ & $\mathrm{Y}$ \\
\hline NCT02736266 (PURE-01) & Pembrolizumab & 2 & cT2-T4N0 & $\mathrm{Y}$ & $\mathrm{N}$ \\
\hline NCT03212651 (PANDORE) & Pembrolizumab & 2 & cT2-T4N0 & $\mathrm{N}$ & $\mathrm{N}$ \\
\hline NCT03319745 & Pembrolizumab & 2 & cT2-T4N0 & $\mathrm{Y}$ & $\mathrm{N}$ \\
\hline \multicolumn{6}{|l|}{ CPI with other immunotherapy } \\
\hline NCT02812420 & Durvalumab + Tremelimumab & 1 & cT2-3aN0 & $\mathrm{Y}$ & $\mathrm{Y}$ \\
\hline NCT03472274 (DUTRENEO) & Durvalumab + Tremelimumab & 2 & cT2-T4N0-1 & $\mathrm{Y}$ & $\mathrm{N}$ \\
\hline NCT03234153 (NITIMIB) & Durvalumab + Tremelimumab & 2 & cTa-T4anyN & $\mathrm{N}$ & $\mathrm{N}$ \\
\hline NCT02845323 & Nivolumab + Urelumab & 2 & cTa-T4N0 & $\mathrm{N}$ & $\mathrm{N}$ \\
\hline NCT03387761 (NABUCCO) & Nivolumab + Ipilimumab & $1 b$ & cTa-T4anyN & $\mathrm{Y}$ & $\mathrm{N}$ \\
\hline NCT03520491 (CA209-9DJ) & Nivolumab + Ipilimumab & 2 & cT2-4aN0 & $\mathrm{N}$ & $\mathrm{N}$ \\
\hline NCT03532451 (PrE0807) & Nivolumab + Lirilumab & $1 b$ & cT2-T4aN0-1 & $\mathrm{Y}$ & $\mathrm{N}$ \\
\hline NCT04209114 (CA045-009) & Nivolumab + Bempeg & 3 & cT2-T4N0 & $\mathrm{N}$ & $\mathrm{N}$ \\
\hline NCT03832673 (PECULIAR) & Pembrolizumab + Epacadostat & 2 & cT2-T3N0 & $\mathrm{Y}$ & $\mathrm{N}$ \\
\hline NCT04586244 (Optimus) & Retifanlimab + Epacadostat & 2 & cT2-T3bN0 & $\mathrm{N}$ & $\mathrm{N}$ \\
\hline NCT04430036 & Zalifrelimab + Balstilimab & 2 & cT2-T4N0-1 & Y & $\mathrm{N}$ \\
\hline
\end{tabular}


Table 4. Cont.

\begin{tabular}{|c|c|c|c|c|c|}
\hline Trial & Agent & Phase & Population & $\begin{array}{l}\text { Cisplatin } \\
\text { Eligibility }\end{array}$ & $\begin{array}{l}\text { Upper-Tract } \\
\text { Disease } \\
\text { Included }\end{array}$ \\
\hline \multicolumn{6}{|l|}{ CPI with chemotherapy } \\
\hline NCT02989584 & Atezolizumab + GC & 2 & cT2-T4aN0 & $\mathrm{Y}$ & $\mathrm{N}$ \\
\hline NCT03674424 (AURA) & Avelumab + Chemotherapy & 2 & cT2-T4anyN & $\mathrm{Y}$ & $\mathrm{N}$ \\
\hline NCT03732677 (NIAGARA) & Durvalumab + GC & 3 & cT2-T4aN0 & $\mathrm{Y}$ & $\mathrm{N}$ \\
\hline NCT03549715 (NEMIO) & $\begin{array}{c}\text { Durvalumab + Tremelimumab + } \\
\text { ddMVAC }\end{array}$ & $1 / 2$ & cT2-T4N0-1 & Y & $\mathrm{N}$ \\
\hline NCT03912818 & Durvalumab + Chemotherapy & 2 & cT2-T4N0-1 & $\mathrm{Y}$ & $\mathrm{N}$ \\
\hline NCT03661320 (ENERGIZE) & Nivolumab + BMS-986205 + GC & 3 & cT2-T4N0 & $\mathrm{Y}$ & $\mathrm{N}$ \\
\hline NCT03294304 (BLASST-1) & Nivolumab + GC & 2 & cT2-T4N0-1 & $\mathrm{Y}$ & $\mathrm{N}$ \\
\hline NCT03558087 & Nivolumab + GC & 2 & cTa-T4N0 & $\mathrm{Y}$ & $\mathrm{N}$ \\
\hline NCT04506554 & Nivolumab + aaMVAC & 2 & cT2-T3N0 & $\mathrm{Y}$ & $\mathrm{N}$ \\
\hline NCT04383743 & Pembrolizumab + MVAC & 2 & cT2-T4N0-1 & $\mathrm{Y}$ & $\mathrm{N}$ \\
\hline NCT02690558 & Pembrolizumab + GC & 2 & cT2-T4N0 & $\mathrm{Y}$ & $\mathrm{N}$ \\
\hline NCT02365766 (HCRN GU14-188) & Pembrolizumab + GC & 2 & cT2-T4N0 & $\begin{array}{l}\mathrm{Y} / \mathrm{N}(\mathrm{two} \\
\text { cohorts) }\end{array}$ & $\mathrm{Y}$ \\
\hline NCT03924856 (KEYNOTE-866) & Pembrolizumab + GC & 3 & cT2-T4N0-1 & $\mathrm{Y}$ & $\mathrm{N}$ \\
\hline NCT04861584 (GZZJU-2021NB) & Teriprizumab + GC & 2 & cT2-T4N0-1 & $\mathrm{Y}$ & $\mathrm{N}$ \\
\hline NCT04730219 & Tislelizumab + Nab-paclitaxel & 2 & cT2-T4aN0 & $\mathrm{Y}$ & $\mathrm{N}$ \\
\hline NCT04553939 & Toripalimab + Gemcitabine & 2 & cT2-T4anyN & $\mathrm{N}$ & $\mathrm{N}$ \\
\hline NCT04099589 & Toripalimab + GC & 2 & cT2-T4aN0 & $\mathrm{Y}$ & $\mathrm{Y}$ \\
\hline \multicolumn{6}{|l|}{ CPI with other agents } \\
\hline NCT04289779 (ABATE) & Atezolizumab + Cabozantinib & 2 & cT2-T4anyN & $\mathrm{N}$ & $\mathrm{N}$ \\
\hline NCT03534492 (NEODURVARIB) & Durvalumab + Olaparib & 2 & cT2-T4aNo & $\mathrm{Y}$ & $\mathrm{N}$ \\
\hline NCT03773666 (BLASST-2) & Durvalumab + Oleclumab & 1 & cT2-T4aN0 & $\mathrm{N}$ & $\mathrm{N}$ \\
\hline NCT04610671 & Nivolumab + CG0070 & 1 & cT2-T4aN0 & $\mathrm{N}$ & $\mathrm{N}$ \\
\hline NCT03518320 & Nivolumab + TAR-200 & 1 & cT2-T3N0-1 & $\mathrm{N}$ & $\mathrm{N}$ \\
\hline $\begin{array}{c}\text { NCT04700124 } \\
\text { (KEYNOTE-B15/EV-304) }\end{array}$ & $\begin{array}{c}\text { Pembrolizumab + Enfortumab } \\
\text { vedotin }\end{array}$ & 3 & cT2-T4N0-1 & $\mathrm{Y}$ & $\mathrm{N}$ \\
\hline $\begin{array}{c}\text { NCT03924895 } \\
\text { (KEYNOTE-905/EV-303) }\end{array}$ & $\begin{array}{c}\text { Pembrolizumab + Enfortumab } \\
\text { vedotin }\end{array}$ & 3 & cT2-T4N0-1 & $\mathrm{N}$ & $\mathrm{N}$ \\
\hline NCT03978624 & Pembrolizumab + Entinostat & 2 & cT2-T4aN0 & $\mathrm{N}$ & $\mathrm{N}$ \\
\hline NA (SURE) & $\begin{array}{l}\text { Pembrolizumab + Sacituzumab } \\
\text { govitecan }\end{array}$ & 2 & cT2-T4N0 & $\mathrm{N}$ & $\mathrm{N}$ \\
\hline NCT04813107 & Tislelizumab + APL-1202 & $1 / 2$ & cT2-T4aN0 & $\mathrm{N}$ & $\mathrm{N}$ \\
\hline \multicolumn{6}{|l|}{ CPI with radiation } \\
\hline NCT04543110 (RADIANT) & Durvalumab + Radiation & 2 & cT2-T4aN0 & $\mathrm{N}$ & $\mathrm{N}$ \\
\hline NCT04779489 (CIRTiN-BC) & CPIs + Radiation & 2 & anyTN+ & $\mathrm{N}$ & $\mathrm{N}$ \\
\hline NCT03529890 (RACE IT) & Nivolumab + Radiation & 2 & cT3-T4anyN & $\mathrm{N}$ & $\mathrm{N}$ \\
\hline
\end{tabular}

\subsection{Immunotherapy Alone}

There have been two pivotal trials of neoadjuvant CPI alone to date [38,39]: The PURE01 trial (NCT02736266) [38] was an open-label, single-arm, phase 2 study that assessed the activity of pembrolizumab as neoadjuvant immunotherapy before RC in patients with MIBC with predominant UC histology and cT2-3bN0 stage. Three cycles of pembrolizumab (200 mg every 3 weeks) were administered to patients before RC. The primary endpoint was pCR. A total of $92 \%$ of patients were eligible for cisplatin. Neoadjuvant pembrolizumab resulted in $42 \% \mathrm{pCR}$ and $54 \%$ downstaging to non-muscle-invasive disease, and toxicity profiles were manageable. A total of $54.3 \%$ of patients with a combined positive score (CPS) $\geq 10$ in programmed death-ligand 1 (PD-L1) expression showed pCR, but only $13.3 \%$ of patients with a PD-L1 CPS $<10$ showed pCR. Recently, a study that evaluated the surgical safety of neoadjuvant pembrolizumab from the PURE-01 study population [40] indicated that high-grade complications (defined as Clavien -Dindo $\geq 3 \mathrm{a}$ ) were observed in $34 \%$ of patients, and that there was no perioperative mortality at 90 days. Survival analysis from PURE-01 revealed that the pembrolizumab effect was maintained post-RC in most patients, with 1- and 2-year event-free survival (EFS) rates of $84.5 \%$ and $71.7 \%$, respectively [41]. A statistically significant EFS benefit was observed in patients with a CR, and high PD-L1 CPS was significantly associated with longer EFS. The ABACUS trial (NCT02662309) [39,42] —a single-arm phase 2 study—investigated the efficacy and 
safety of two cycles of neoadjuvant atezolizumab (1200 mg every 3 weeks) prior to RC for MIBC (T2-4N0M0). The primary endpoint was pCR. Unlike PURE-01, all patients were ineligible for or refused cisplatin-based NAC. The rate of $\mathrm{pCR}$ and downstaging to non-muscle-invasive disease were $31 \%$ and $39 \%$, respectively. Treatment-related grade $3 / 4$ toxicity occurred in $12 \%$ of patients. Grade 3 or 4 surgical complications occurred in $31 \%$ of patients. Meanwhile, the combination of CPI therapy with other agents (other immunotherapy, chemotherapy, or other agents such as targeted therapy) in a neoadjuvant setting is being actively investigated.

\subsection{Combination of Immunotherapy and Another Immunotherapy}

Cytotoxic T-lymphocyte antigen 4 (CTLA-4), another key immune checkpoint, is expressed by activated T cells and regulatory T cells. Binding of CTLA-4 to its ligands (B7-1 (also known as CD80) and B7-2 (also known as CD86)) on antigen-presenting cells leads to inhibition of $\mathrm{T}$ cells [43]. Blocking of the T-cell negative regulator CTLA-4 allows CD28 and B7 interactions, which result in T-cell activation, proliferation, tumor infiltration and, ultimately, cancer cell death [44]. CTLA-4 inhibits the early activation and differentiation of T cells (typically in the lymph nodes), whereas programmed cell death protein 1 (PD-1) modulates their effector functions (mostly within tumors), which can lead to T-cell exhaustion [45]. Therefore, the combination of anti-PD-1 and CTLA-4 therapy triggers complementary mechanisms of therapeutic checkpoint inhibition [46]. In preclinical models, combined blockade of PD- 1 and CTLA- 4 achieved more pronounced antitumor activity than the blockade of either pathway alone [47,48]. Furthermore, the combination of CTLA-4 and PD-1/PD-L1 inhibitors showed promising clinical activity in several clinical trials [49]. In this context, a combination strategy of CTLA-4 and PD-1/PD-L1 inhibitors is being investigated extensively in neoadjuvant settings for MIBC.

The NABUCCO trial (NCT03387761) —a single-arm feasibility trial—assessed neoadjuvant ipilimumab/nivolumab combination therapy [50]. A total of 24 patients with stage III UC were treated with $3 \mathrm{mg} / \mathrm{kg}$ ipilimumab (day 1) plus $3 \mathrm{mg} / \mathrm{kg}$ ipilimumab, $1 \mathrm{mg} / \mathrm{kg}$ nivolumab (day 22), and $3 \mathrm{mg} / \mathrm{kg}$ nivolumab (day 43), followed by resection. The primary endpoint was feasibility to resect within 12 weeks of the start of treatment. A total of $96 \%$ of patients underwent resection within 12 weeks, and grade 3-4 immune-related adverse events (AEs) occurred in $55 \%$ of patients. Furthermore, a total of $46 \%$ of patients showed $\mathrm{pCR}$, and $58 \%$ had no remaining invasive disease (pCR or $\mathrm{pTisN0/pTaN0).} \mathrm{DUTRENEO}$ (NCT03472274) was a randomized phase 2 trial of durvalumab (DU)/tremelimumab (TRE) vs. chemotherapy in the neoadjuvant setting [51]. Cisplatin-eligible patients with cT2T4aN0-1 were classified as immunologically "hot" or "cold" according to a tumor immune score devised by NanoString Technologies. Patients with "hot" tumors were randomized to three cycles of $1500 \mathrm{mg}$ DU $+75 \mathrm{mg}$ TRE every 4 weeks or standard cisplatin-based NAC. Patients in the "cold" arm received cisplatin-based NAC. The primary endpoint was pCR in the DU/TRE arm. In the "hot" arm, 36.4\% of NAC and 34.8\% of DU/TRE had a pCR, while $68.8 \%$ of patients in the NAC "cold" arm had a pCR. Grade 3-4 toxicities were more frequent in the NAC group.

Until recently, combination treatment with PD-1/PD-L1 and CTLA-4 inhibitors has been studied extensively; however, newer strategies are now being investigated in the neoadjuvant setting, such as combination treatment with epacadostat, BMS-986205 (IDO-1 inhibitor), or NKTR-214/BEMPEG (CD122-preferential IL-2 pathway agonist).

\subsection{Combination of Immunotherapy and Cytotoxic Chemotherapy}

Neoadjuvant immunotherapy with cytotoxic chemotherapy is being extensively investigated. Conventional chemotherapy can stimulate tumor-specific immune responses either by inducing immunogenic cell death (ICD) of tumor cells or by engaging immune effector mechanisms [52]. ICD, with several mechanisms-including exposure of calreticulin to the outer cell surface; release of adenosine triphosphate, annexin-1, and high-mobility group box 1 protein; autophagy; inflammasome activation; induction of type 1 interferon 
signaling, and release of mitochondrial formyl peptides-induces premortem reticular stress and releases tissue-damage-denoting substances (alarmins) that alert the immune system [53]. Furthermore, conventional chemotherapy can promote the activation of immune effector cells, hamper the functions of immunosuppressive cells, or alter whole-body physiology through the promotion and/or activation of mechanisms that ultimately support immunological competence [54]. These results provide a scientific rationale for the investigation of the combination of chemotherapy and immunotherapy; thus, many trials are currently ongoing.

BLASST-1 (NCT03294304) was a phase 2, single-arm trial that investigated the efficacy and safety of nivolumab with GC as neoadjuvant therapy for MIBC (cT2-T4aN $\leq 1 \mathrm{M} 0$ ) [55] Patients received four cycles of GC with nivolumab every 3 weeks, followed by RC within 8 weeks. The primary endpoint was $\mathrm{PaR}(\leq \mathrm{pT} 1 \mathrm{~N} 0)$; $\mathrm{PaR}$ was observed in $65.8 \%$ of patients, including those with $\mathrm{N} 1$ disease. The combination was safe, with manageable toxicities and no deaths from treatment. The majority of AEs were from GC; the overall rate of grade 3-4 AEs was 20\%. One patient developed Guillain-Barré syndrome after surgery, which was resolved with intravenous immunoglobulin. There was no time delay to RC and no unexpected surgical complications from treatment. HCRN GU14188 (NCT02365766) was a phase $1 \mathrm{~b} / 2$ trial that evaluated the tolerability and efficacy of neoadjuvant GC with pembrolizumab in MIBC (cT2-4aN0M0) [56,57]. This study comprised two cohorts: cohort 1 was cisplatin-eligible, and cohort 2 was cisplatin-ineligible. Recently, the results of cohort 1 were reported: The primary endpoint was $\operatorname{PaR}(\leq \mathrm{pT} 1 \mathrm{~N} 0)$. $\mathrm{PaR}$ and $\mathrm{pCR}$ were observed in $61.1 \%$ and $44.4 \%$ of patients, respectively; PaR occurred in $53 \%$ of cT2 and $74 \%$ of cT3/4. The median time to RC from the last dose was 5.3 weeks. There was one death on post-RC day 9 due to mesenteric ischemia. At a median follow-up of 34.2 months, the estimated rates of 36-month relapse-free survival and OS were $63 \%$ and $82 \%$, respectively. Currently, there are three ongoing phase 3 trials of neoadjuvant immunotherapy combined with cisplatin-based chemotherapy (NIAGARA [NCT03732677], ENERGIZE [NCT03661320], and KEYNOTE-866 [NCT03924856]), but their results have yet to be reported. Meanwhile, several ongoing studies are investigating immunotherapy with non-cisplatin-based chemotherapy, including nab-paclitaxel and gemcitabine as neoadjuvant treatments.

\subsection{Combination of Immunotherapy and Antibody-Drug Conjugates (ADCs)}

ADCs are complex engineered therapeutics consisting of monoclonal antibodies directed toward tumor-associated antigens, to which highly potent cytotoxic agents are attached using chemical linkers [58]. Recently, several studies of ADCs in mUC have shown promising results.

Enfortumab vedotin is an ADC that comprises a fully human monoclonal antibody conjugated to a clinically validated microtubule-disrupting agent-monomethyl auristatin E-via a protease-cleavable linker [59]. Nectin-4-a type I transmembrane protein and member of a family of related immunoglobulin-like adhesion molecules-is known to be overexpressed in several epithelial cancers, especially bladder and breast cancer. However, the expression of nectin- 4 in normal tissue is more limited. Enfortumab vedotin was able to bind to cell-surface-expressed nectin-4 with high affinity and induce cell death [60]. EV-201 (NCT03219333) is a global, phase 2, single-arm study that administered $1.25 \mathrm{mg} / \mathrm{kg}$ enfortumab vedotin (intravenously on days 1,8 , and 15 of every 28-day cycle) to patients with locally advanced or metastatic UC who were previously treated with platinum chemotherapy and anti-PD-1/PD-L1 therapy [59]. The primary endpoint was objective response rate (ORR). The confirmed ORR was $44 \%$, including $12 \%$ with radiographic complete response (CR). Based on the results of EV-201, EV-301 (NCT03474107) was conducted; EV-301 is a global, open-label, phase 3 study that investigated enfortumab vedotin vs. chemotherapy in patients with locally advanced or metastatic UC who had previously received platinum-containing chemotherapy, and had disease progression during or after PD-1/PD-L1 inhibitor treatment [61]. Patients were randomly assigned to groups (1:1) to 
receive enfortumab vedotin or the investigator's choice of standard docetaxel, paclitaxel, or vinflunine chemotherapy. The primary endpoint was OS. After an 11.1-month follow-up period, median OS was significantly prolonged by 3.9 months with enfortumab vedotin compared with chemotherapy (median OS: 12.9 vs. 9.0 months); similar OS benefits were observed in prespecified subgroups. PFS was also improved with enfortumab vedotin vs. chemotherapy (5.6 vs. 3.7 months). Both ORR and disease control rate were significantly higher with enfortumab vedotin vs. chemotherapy $(40.6 \%$ vs. $17.9 \%$ and $71.9 \%$ vs. $53.4 \%$, respectively; one-sided $p<0.001)$. Rates of treatment-related adverse events (TRAEs; $93.9 \%$ vs. $91.8 \%$ ), including serious TRAEs ( $22.6 \%$ vs. $23.4 \%$ ), were comparable between the enfortumab vedotin and chemotherapy groups. The FDA granted accelerated approval to enfortumab vedotin to treat patients with locally advanced or metastatic UC who previously received a PD-1/PD-L1 inhibitor and platinum-containing chemotherapy in the neoadjuvant/adjuvant, locally advanced, or metastatic settings. Based on these promising results, two randomized phase 3 trials of perioperative enfortumab vedotin with pembrolizumab vs. chemotherapy in cisplatin-eligible patients (NCT04700124) —or observation in cisplatin-ineligible patients (NCT03924895) - are ongoing in MIBC.

Sacituzumab govitecan is an ADC that recognizes trophoblast cell-surface antigen 2 (Trop-2) - a cell-surface glycoprotein highly expressed in aggressive bladder cancers. The antibody to Trop- 2 is conjugated with a linker to a payload consisting of SN-38-the active metabolite of irinotecan [62,63]. Scott et al. performed a phase $1 / 2$ basket study (NCT01631552) on patients with advanced solid tumors receiving intravenous sacituzumab govitecan administered on days 1 and 8 of 21-day cycles until progression or unacceptable toxicity, and reported the results of patients with mUC [64]. The ORR was $31 \%$ and the median PFS and OS were 7.3 and 18.9 months, respectively. TROPHY-U-01 (NCT03547973) is a multicohort, global, open-label phase 2 study evaluating the clinical activity of sacituzumab govitecan in patients with unresectable, locally advanced or metastatic UC. The results of cohort 1 -which includes patients progressing after platinum and CPI therapy with unlimited prior lines of therapy-were recently reported [65]. The ORR, primary endpoint of this study, was $27 \%$, including $5 \%$ with CR. Cohort 3 of this trial, which is actively accruing patients, is investigating the clinical benefit of sacituzumab govitecan in combination with pembrolizumab in the second-line setting [66]. On 13 April, 2021, the FDA granted accelerated approval to sacituzumab govitecan for patients with locally advanced or metastatic UC who previously received platinum-containing chemotherapy and either a PD-1 or a PD-L1 inhibitor. Based on the promising results of sacituzumab govitecan in the metastatic setting, the SURE trial has been planned; this trial is an open-label, sequential-arm, phase 2 study of neoadjuvant sacituzumab govitecan and sacituzumab govitecan plus pembrolizumab before RC for patients with MIBC who cannot receive or refuse cisplatin-based chemotherapy [67].

\subsection{Combination of Immunotherapy and Other Emerging Agents or Radiotherapy}

NEODURVARIB (NCT03534492) was a single-arm, phase 2 trial that assessed the impact of neoadjuvant durvalumab plus olaparib (a poly ADP-ribose polymerase inhibitor) in MIBC (cT2-T4aN0) [68]. Patients received $1500 \mathrm{mg}$ durvalumab every 4 weeks for up to a maximum of 2 months (up to 2 doses/cycle) plus $300 \mathrm{mg}$ olaparib for up to 56 days (two cycles of 28 days each cycle). The primary endpoint was pCR rate, which was $44.5 \%$. One death related to postoperative complications was reported. Grade 3-4 AEs were detected in only $8.3 \%$ of patients. ABATE (NCT04289779) is an open-label, single-arm study to assess the efficacy and safety of cabozantinib (tyrosine kinase inhibitor whose targets include MET, AXL, and VEGFR2) with atezolizumab as neoadjuvant therapy for cT2-T4aN0/xM0 advanced UC patients who are either cisplatin-ineligible or decline cisplatin [69]. The primary endpoint is downstaging to non-muscle-invasive disease $(<\mathrm{pT} 2)$. This study is ongoing, and results are not yet reported.

Genomic alterations in the oncogenic fibroblast growth factor receptor (FGFR) 3 pathway are well described in UC, and have led to extensive investigations of FGFR3-targeted 
therapies [70]. In the metastatic setting, several studies assessed the clinical benefit of FGFR inhibitors. The BLC2001 trial (NCT02365597) —an open-label phase 2 study—assessed the response in patients with locally advanced and unresectable or metastatic UC with FGFR alterations [71]. The confirmed response rate to erdafitinib therapy was $40 \%$ (3\% with a CR and $37 \%$ with a partial response). Among the 22 patients who had undergone previous immunotherapy, the confirmed response rate was $59 \%$. Currently, there are no studies of neoadjuvant FGFR-targeted agents with immunotherapy combination in muscle-invasive disease. There are some concerns about FGFR-targeted therapy being a proper partner of immunotherapy, as FGFR pathway activation is associated with non-T-cell-inflamed tumors in MIBC [72]. In the perioperative setting, only infigratinib (FGFR1-3-selective tyrosine kinase inhibitor) monotherapy is currently being investigated as neoadjuvant (NCT0422804) and adjuvant (NCT04197986) treatment for locally advanced UC.

Many efforts to find an appropriate partner for CPI therapy in the neoadjuvant setting are underway. There are several trials involving emerging agents-including CD73 inhibitor (NCT03773666), replication-competent oncolytic adenovirus (NCT04610671), and synthetic benzamide-derivative histone deacetylase inhibitor (NCT03978624). These studies are currently ongoing, and the results have not yet been reported.

Radiation can synergize with immunotherapy to improve oncological outcomes by causing ICD and increasing immune marker expression [73]. Based on this hypothesis, several trials of neoadjuvant immunotherapy with radiotherapy (RT) prior to cystectomy in MIBC are being conducted. RADIANT (NCT04543110) assesses the effect of sequential radiation and durvalumab immunotherapy given as treatment prior to surgery with RC for patients with bladder cancer who are unfit for or decline cisplatin. The RACE IT (NCT03529890, nivolumab + radiotherapy) and CIRTiN-BC (NCT04779489, several CPIs + radiotherapy) trials are also ongoing.

\section{Adjuvant Immunotherapy in MIBC}

There are three large-scale, randomized phase 3 trials for adjuvant immunotherapy (Table 5). The IMvigor 010 study (NCT02450331)—a multicenter, open-label, randomized phase 3 trial-evaluates atezolizumab for adjuvant therapy in patients with high-risk muscle-invasive UC (MIUC) [74]. Patients had ypT2-4a or ypN+ tumors following NAC or pT3-4a or $\mathrm{pN}+$ tumors if no NAC was administered. Patients not treated with NAC must have been ineligible for or declined cisplatin-based NAC. A total of 807 patients were randomly assigned (1:1) to receive $1200 \mathrm{mg}$ atezolizumab administered intravenously every 3 weeks for 16 cycles, up to one year, or to observation (whichever occurred first). A total of $6.6 \%$ patients had upper-tract MIUC. The primary endpoint was DFS; the trial did not meet its primary endpoint, with a nonsignificant difference in DFS between the atezolizumab group (19.4 months) and observation (16.6 months). Atezolizumab was generally tolerable, and had no new safety signals.

Table 5. Summary of phase 3 trials for adjuvant immunotherapy in muscle-invasive bladder cancer.

\begin{tabular}{ccccccc}
\hline Trial & Phase & Agent & Control & N & $\begin{array}{c}\text { Primary } \\
\text { Endpoint }\end{array}$ & $\begin{array}{c}\text { Cisplatin- } \\
\text { Based } \\
\text { NAC }\end{array}$ \\
\hline $\begin{array}{c}\text { NCT03244384 [76] } \\
\text { (AMBASSADOR) }\end{array}$ & 3 & Pembrolizumab & Observation & 739 & OS, DFS & Included \\
$\begin{array}{c}\text { NCT02632409 [75] } \\
\text { (CheckMate 274) }\end{array}$ & 3 & Nivolumab & Placebo & 700 & DFS & Included \\
$\begin{array}{c}\text { NCT02450331 [74] } \\
\text { (IMvigor010) }\end{array}$ & 3 & Atezolizumab & Observation & 809 & DFS & Included \\
\hline
\end{tabular}

The CheckMate 274 trial (NCT02632409) is a recent randomized, double-blind, multicenter phase 3 trial of nivolumab vs. placebo in patients with high-risk MIUC after radical surgery, which reported positive results [75]. Patients had ypT2-4a or ypN+ tumors following NAC or pT3-4a or $\mathrm{pN}+$ tumors if no NAC was administered. Patients were randomly 
(1:1) assigned to groups that received $240 \mathrm{mg}$ nivolumab every 2 weeks or placebo for $\leq 1$ year of adjuvant treatment. Patients had radical surgery within 120 days \pm neoadjuvant cisplatin, or were ineligible for/declined cisplatin-based chemotherapy. The primary endpoints were DFS in all randomized patients and patients with tumor PD-L1 expression $\geq 1 \%$. A total of $21 \%$ of patients had upper-tract UC. The primary endpoint of DFS was met in all randomized patients (median $=21.0$ months for nivolumab, 10.9 months for placebo; hazard ratio $(\mathrm{HR})=0.70 ; p<0.001)$ and in patients with PD-L1 $\geq 1 \%$ (median not reached for nivolumab, 10.8 months for placebo; HR $=0.53 ; p<0.001$ ). DFS improvement with nivolumab was generally consistent across subgroups. Grade $3-4$ TRAEs occurred in $17.9 \%$ and $7.2 \%$ of patients in the nivolumab and placebo arms, respectively.

Although the IMvigor 010 (NCT02450331) and CheckMate 274 trials (NCT02632409) were similar in design, they showed conflicting results. These two trials had some differences in population and study design. CheckMate 274 included more upper tract disease than IMvigor 010 (6.6\% in IMvigor 010 vs. 21\% in CheckMate 274). In addition, CheckMate 274 was a placebo-controlled study, while IMvigor 010 was an observation-controlled study. In fact, the DFS of the experimental arm was similar in the two studies (19.4 months with atezolizumab (IMvigor 010) vs. 21.0 months with nivolumab (CheckMate 274)), but the DFS of their control groups showed a difference of approximately 6 months (16.6 months with observation (IMvigor 010) vs. 10.9 months with placebo (CheckMate 274)). Given that it is not appropriate to compare the two trials directly, these conflicting results should be interpreted cautiously. The AMBASSADOR (NCT03244384) trial-a multicenter, randomized phase 3 trial of adjuvant pembrolizumab vs. observation-is currently ongoing in patients with high-risk MIUC [76]. The results of this study are not yet reported.

Currently, the use of adjuvant immunotherapy with other agents is not being actively investigated. Instead of the "adjuvant-only" setting, adjuvant immunotherapy with other agents is being researched in conjunction with the neoadjuvant approach. We have summarized the major phase 3 trials involving perioperative (sequential) immunotherapy with other agents in Table 6.

Table 6. Summary of phase 3 trials for perioperative sequential treatment.

\begin{tabular}{|c|c|c|c|}
\hline Trial & Phase & Agent & Arm \\
\hline $\begin{array}{l}\text { NCT04209114 } \\
\text { (CA045-009) }\end{array}$ & 3 & Nivolumab + Bempeg & $\begin{array}{c}\text { Arm A: Neoadjuvant nivolumab }+ \text { bempeg }=>R C=>\text { Adjuvant } \\
\text { nivolumab }+ \text { bempeg } \\
\text { Arm B: Neoadjuvant nivolumab }=>R C=>\text { Adjuvant nivolumab } \\
\text { Arm } C: R C \text { alone }\end{array}$ \\
\hline $\begin{array}{l}\text { NCT03732677 } \\
\text { (NIAGARA) }\end{array}$ & 3 & Durvalumab + GC & $\begin{array}{c}\text { Arm A: Neoadjuvant durvalumab }+\mathrm{GC}=>\mathrm{RC}=>\text { Adjuvant } \\
\text { durvaluamb } \\
\text { Arm B: Neoadjuvant } \mathrm{GC}=>\mathrm{RC}=>\text { No adjuvant therapy }\end{array}$ \\
\hline $\begin{array}{l}\text { NCT03661320 } \\
\text { (ENERGIZE) }\end{array}$ & 3 & Nivolumab + BMS-986205 + GC & $\begin{array}{c}\text { Arm A: Neoadjuvant } \mathrm{GC}=>\mathrm{RC}=>\text { No adjuvant therapy } \\
\text { Arm B: Neoadjuvant nivolumab }+ \text { placebo }+\mathrm{GC}=>\mathrm{RC}=> \\
\text { Adjuvant nivolumab + placebo } \\
\text { Arm C: Neoadjuvant nivolumab }+ \text { BMS-986205 }+\mathrm{GC}=>\mathrm{RC}=> \\
\text { Adjuvant nivolumab + BMS-986205 }\end{array}$ \\
\hline $\begin{array}{l}\text { NCT03924856 } \\
\text { (KEYNOTE-866) }\end{array}$ & 3 & Pembrolizumab + GC & $\begin{array}{l}\text { Arm A: Neoadjuvant pembrolizumab }+\mathrm{GC}=>\mathrm{RC}=>\text { Adjuvant } \\
\text { pembrolizumab } \\
\text { Arm B: Neoadjuvant placebo }+\mathrm{GC}=>\mathrm{RC}=>\text { Adjuvant placebo }\end{array}$ \\
\hline $\begin{array}{c}\text { NCT04700124 } \\
\text { (KEYNOTE-B15/EV-304) }\end{array}$ & 3 & $\begin{array}{c}\text { Pembrolizumab + Enfortumab } \\
\text { vedotin }\end{array}$ & $\begin{array}{c}\text { Arm A: Neoadjuvant pembrolizumab + enfortumab vedotin }=> \\
\text { RC }=>\text { Adjuvant pembrolizumab + enfortumab vedotin } \\
\text { Arm B: Neoadjuvant } G C=>R C=>\text { No adjuvant therapy }\end{array}$ \\
\hline $\begin{array}{c}\text { NCT03924895 } \\
\text { (KEYNOTE-905/EV-303) }\end{array}$ & 3 & $\begin{array}{c}\text { Pembrolizumab + Enfortumab } \\
\text { vedotin }\end{array}$ & $\begin{array}{c}\text { Arm A: Neoadjuvant pembrolizumab }+ \text { enfortumab vedotin }=> \\
\text { RC }=>\text { Adjuvant pembrolizumab }+ \text { enfortumab vedotin } \\
\text { Arm B: Neoadjuvant pembrolizumab }=>R C=>\text { Adjuvant } \\
\text { pembrolizumab } \\
\text { Arm C: RC alone }\end{array}$ \\
\hline
\end{tabular}




\section{Discussion}

Perioperative CPI therapy, with or without other agents, has shown promising clinical efficacy and safety in several trials. However, several unanswered questions remain: The first is whether a perioperative CPI-based approach can replace perioperative cisplatin-based chemotherapy in cisplatin-eligible patients. The PURE-01 [38] and ABACUS [39] studies on single-agent neoadjuvant immunotherapy revealed pCR rates of $30-40 \%$. Meanwhile, GETUG-AFU (NCT01812369) showed 35-45\% pCR rates with cisplatin-based NAC [21] (Table 7). Considering these data, it is unclear whether singleagent neoadjuvant CPI therapy is superior to cisplatin-based NAC in patients who are fit for cisplatin. However, whether pCR is an optimal endpoint for neoadjuvant CPI trials is also not well established. The effects of immunotherapy can last longer than those of cytotoxic agents; therefore, long-term follow-up and survival results can provide a clinical impression about the efficacy of neoadjuvant immunotherapy in the future. Meanwhile, although adjuvant nivolumab showed clinical benefits in patients unfit for cisplatin in the adjuvant setting (patients who received cisplatin-based NAC were unfit for cisplatin in the adjuvant setting), it is unclear whether adjuvant nivolumab is superior to cisplatin in patients who are fit for cisplatin. Although it is also not appropriate to directly compare two different studies in terms of numerical HR difference, EORTC 30994 [22] exhibited a numerically lower HR (DFS, HR, 0.54 with GC vs. 0.70 with nivolumab) than CheckMate 274 [75]. However, CheckMate 274 exhibited a numerically comparable HR (0.53) in PD-L1-positive patients.

Table 7. Summary of pathologic response in major neoadjuvant trials.

\begin{tabular}{|c|c|c|c|c|c|c|c|c|c|c|}
\hline & \multirow{2}{*}{$\begin{array}{c}\text { Pure-01 } \\
{[38,41]}\end{array}$} & \multirow{2}{*}{$\begin{array}{c}\text { ABACUS } \\
{[39,42]} \\
\text { ATEZO }\end{array}$} & \multirow{2}{*}{$\begin{array}{c}\text { NABUCCO } \\
\text { [50] } \\
\text { IPI/NIVO }\end{array}$} & \multirow{2}{*}{$\begin{array}{l}\text { DUTRENEO } \\
\text { [51] } \\
\text { DU/TREME }\end{array}$} & \multirow{2}{*}{$\begin{array}{c}\begin{array}{c}\text { BLASST-1 } \\
{[55]}\end{array} \\
\mathrm{NIVO}+\mathrm{GC}\end{array}$} & \multicolumn{2}{|c|}{$\begin{array}{c}\text { HCRN GU14-188 } \\
{[56,57]}\end{array}$} & \multirow{2}{*}{$\begin{array}{c}\begin{array}{c}\text { SWOG8710 } \\
{[6]}\end{array} \\
\text { MVAC }\end{array}$} & \multicolumn{2}{|c|}{$\begin{array}{c}\text { GETUG/AFU } \\
{[21]}\end{array}$} \\
\hline & & & & & & $\begin{array}{c}\text { Cohort } \\
\text { 1: PEM } \\
+ \text { GC }\end{array}$ & $\begin{array}{l}\text { Cohort } \\
\text { 2: PEM } \\
+ \text { GEM }\end{array}$ & & $\begin{array}{c}\text { Arm A: } \\
\text { ddM- } \\
\text { VAC }\end{array}$ & $\begin{array}{l}\text { ARM B: } \\
\text { GC }\end{array}$ \\
\hline $\mathrm{N}$ & 143 & 88 & 24 & 23 & 41 & 43 & 37 & 317 & 248 & 245 \\
\hline $\mathrm{pCR}(\%)$ & 39 & 31 & 46 & 35 & 49 & 44 & 45 & 38 & 42 & 36 \\
\hline $\begin{array}{l}\text { Downstaging } \\
(<\mathrm{pT} 2)(\%)\end{array}$ & 56 & 39 & 58 & 57 & 66 & 61 & 52 & NA & 63 & 49 \\
\hline
\end{tabular}

However, the recent trend for perioperative trials is a combination strategy. Therefore, comparing the superiority of perioperative immunotherapy and chemotherapy may be inappropriate in this era of immunotherapy. It is necessary to check the results of the ongoing trials to determine whether a perioperative combination strategy can eventually become the standard of care.

The second issue associated with the perioperative setting is determining whether neoadjuvant or adjuvant treatment is appropriate. Although several guidelines prefer NAC over AC, there is no consensus on whether neoadjuvant or adjuvant immunotherapy is appropriate. Both approaches present potential advantages: Neoadjuvant treatment [77] enables less extensive surgery, response monitoring, and provides prognostic information, including $\mathrm{pCR}$ and surrogate markers. Furthermore, the neoadjuvant approach might be better tolerated than the adjuvant approach, owing to the relevant post-surgery morbidity that might prevent reasonable adjuvant treatment. Moreover, immunotherapy may be more appropriate in the neoadjuvant setting than in the adjuvant setting; this is because of the hypothesis that tumor-infiltrating lymphocytes mostly express the targets for immunotherapy; moreover, a higher load of tumor antigens is likely to be present when the primary tumor is still present for cross-priming at the time of immunotherapy [78]. However, the major concern for neoadjuvant treatment is delaying potentially curative RC in a proportion of patients - particularly those with symptoms and at risk of rapid clinical deterioration. According to the Keynote 052 trial [33], CPI monotherapy exhibited only $20 \%$ ORR in patients with metastatic disease who were treatment-naïve, and approximately 
$40 \%$ of patients were initially refractory to CPI therapy. Therefore, refractoriness to neoadjuvant immunotherapy is a major challenge that may interfere with treatment. Meanwhile, adjuvant treatment also has several advantages, including not delaying curative surgery, and treatment decision-making based on pathologic staging; however, adjuvant treatment cannot be delivered to patients who have had extensive surgeries, as it can increase the risk of postoperative complications and worsen performance status. Considering the pros and cons of these treatments, many ongoing perioperative trials are not confined to only the "one-side" strategy (neoadjuvant or adjuvant), and are being conducted with consecutive treatment strategies, ranging from neoadjuvant to adjuvant therapy.

Finally, a prognostic or predictive biomarker analysis may improve the efficacy of the perioperative strategy. There have been several efforts to investigate the molecular prognostic factors in MIBC. For example, p53 has been investigated as a prognostic marker of MIBC in several retrospective studies $[79,80]$. However, the evidence is lacking for the clinical utility of p53 as a prognostic marker. A previous trial, which investigated the prognostic impact of p53 in the adjuvant setting, failed to show the prognostic value of p53 [25]. The Cancer Genome Atlas (TCGA) project performed an integrated analysis of 131 UCs with whole genome/RNA sequencing, microarray, and reverse-phase protein array [81]; this study identified four clusters of UCs: Cluster I ("papillary like") was enriched in tumors with papillary morphology and FGFR3 mutations/copy numbers/expression. Clusters I and II expressed high human epidermal growth factor receptor 2 (HER2; ERBB2) levels and an elevated estrogen receptor beta signaling signature. Cluster III ("basal/squamouslike") was similar to that of basal-like breast cancers, as well as squamous-cell cancers of the head, neck, and lung. Until now, there are no definitive prognostic biomarkers in MIBC. However, given these results, future studies based on precision medicine should be performed. Currently, there are several ongoing molecular-biomarker-driven studies in the perioperative setting.

Currently, there is no consensus on predictive biomarkers in the perioperative setting. Previous studies $[28,30,31,33,35,82-87]$ have suggested several potential biomarkers of immunotherapy in the metastatic setting, including PD-L1 expression, molecular subtyping, tumor mutation burden, gene expression subtype, and DNA damage response gene alteration; however, the reliability of predictive biomarkers remains dubious in the perioperative and metastatic settings.

In the perioperative setting, the PURE-01 trial reported a significant nonlinear association between tumor mutation burden and pT0, and a cutoff at 15 mutations $/ \mathrm{Mb}$ [38]. The ABACUS trial proposed that preexisting activated $\mathrm{T}$ cells were more prominent than expected, and correlated with better outcomes [42]. Additionally, IMvigor 011 suggested that post-surgical ctDNA positivity, which is associated with a high risk of recurrence and death, identified patients with MIUC that were likely to benefit from adjuvant atezolizumab [88]. Many ongoing trials are currently exploring potential biomarkers; we hope that these analyses will contribute to clinical improvement in patients who receive perioperative treatment.

\section{Conclusions}

Given the recurrence rates and poor outcomes of treatment with RC alone for MIBC, perioperative systemic treatment is important for improving the prognosis of patients with MIBC. Cisplatin-based perioperative chemotherapy is currently the primary perioperative strategy, and it is expected to be of significance in the future. Owing to the success of CPI therapy in advanced UC, perioperative immunotherapy has been extensively studied in MIBC. Perioperative immunotherapy has shown promising efficacy with relatively low toxicity. Furthermore, immunotherapy-based combination strategies have shown encouraging results. As novel agents including ADCs have recently shown promising results in UC, they are likely to be emerging options in the perioperative setting. We expect that the ongoing perioperative trials will achieve positive results and improve the prognosis of patients with MIBC. 
Author Contributions: All co-authors contributed by drafting parts of the manuscript. All co-authors approved the final version of the document. All authors have read and agreed to the published version of the manuscript.

Funding: This work was supported by the National Research Foundation of Korea (NRF) grant funded by the Korean Government (MSIT) (No. 2017R1A5A2015385).

Conflicts of Interest: The authors declare no conflict of interest.

\section{References}

1. Bray, F.; Ferlay, J.; Soerjomataram, I.; Siegel, R.L.; Torre, L.A.; Jemal, A. Global cancer statistics 2018: GLOBOCAN estimates of incidence and mortality worldwide for 36 cancers in 185 countries. CA Cancer J. Clin. 2018, 68, 394-424. [CrossRef] [PubMed]

2. Patel, V.G.; Oh, W.K.; Galsky, M.D. Treatment of muscle-invasive and advanced bladder cancer in 2020. CA A Cancer J. Clin. 2020, 70, 404-423. [CrossRef] [PubMed]

3. Stein, J.P.; Lieskovsky, G.; Cote, R.; Groshen, S.; Feng, A.C.; Boyd, S.; Skinner, E.; Bochner, B.; Thangathurai, D.; Mikhail, M.; et al. Radical cystectomy in the treatment of invasive bladder cancer: Long-term results in 1,054 patients. J. Clin. Oncol. Off. J. Am. Soc. Clin. Oncol. 2001, 19, 666-675. [CrossRef] [PubMed]

4. Witjes, J.A.; Bruins, H.M.; Cathomas, R.; Compérat, E.M.; Cowan, N.C.; Gakis, G.; Hernández, V.; Linares Espinós, E.; Lorch, A.; Neuzillet, Y.; et al. European Association of Urology Guidelines on Muscle-invasive and Metastatic Bladder Cancer: Summary of the 2020 Guidelines. Eur. Urol. 2021, 79, 82-104. [CrossRef]

5. National Comprehensive Cancer Network (NCCN). NCCN Clinical Practice Guidelines in Oncology. Bladder Cancer Version 3. 2021. Available online: https:/ / www.nccn.org/professionals/physician_gls/pdf/bladder.pdf (accessed on 22 April 2021)

6. Grossman, H.B.; Natale, R.B.; Tangen, C.M.; Speights, V.O.; Vogelzang, N.J.; Trump, D.L.; deVere White, R.W.; Sarosdy, M.F.; Wood, D.P., Jr.; Raghavan, D.; et al. Neoadjuvant chemotherapy plus cystectomy compared with cystectomy alone for locally advanced bladder cancer. N. Engl. J. Med. 2003, 349, 859-866. [CrossRef]

7. Sherif, A.; Holmberg, L.; Rintala, E.; Mestad, O.; Nilsson, J.; Nilsson, S.; Malmström, P.U. Neoadjuvant cisplatinum based combination chemotherapy in patients with invasive bladder cancer: A combined analysis of two Nordic studies. Eur. Urol. 2004, 45, 297-303. [CrossRef]

8. Griffiths, G.; Hall, R.; Sylvester, R.; Raghavan, D.; Parmar, M.K. International phase III trial assessing neoadjuvant cisplatin, methotrexate, and vinblastine chemotherapy for muscle-invasive bladder cancer: Long-term results of the BA06 30894 trial. $J$. Clin. Oncol. Off. J. Am. Soc. Clin. Oncol. 2011, 29, 2171-2177.

9. Finnbladder, N.B.C.S.G.; de Tratamiento Oncologico, C.U.E.; EORTC Genito-Urinary Group; Australian Bladder Cancer Study Group; National Cancer Institute of Canada Clinical Trials Group. Neoadjuvant cisplatin, methotrexate, and vinblastine chemotherapy for muscle-invasive bladder cancer: A randomised controlled trial. International collaboration of trialists. Lancet 1999, 354, 533-540.

10. Neoadjuvant chemotherapy in invasive bladder cancer: A systematic review and meta-analysis. Lancet 2003, 361, 1927-1934. [CrossRef]

11. Winquist, E.; Kirchner, T.S.; Segal, R.; Chin, J.; Lukka, H. Neoadjuvant chemotherapy for transitional cell carcinoma of the bladder: A systematic review and meta-analysis. J. Urol. 2004, 171, 561-569. [CrossRef]

12. Neoadjuvant chemotherapy in invasive bladder cancer: Update of a systematic review and meta-analysis of individual patient data advanced bladder cancer (ABC) meta-analysis collaboration. Eur. Urol. 2005, 48, 202-205, discussion 205-206. [CrossRef] [PubMed]

13. Choueiri, T.K.; Jacobus, S.; Bellmunt, J.; Qu, A.; Appleman, L.J.; Tretter, C.; Bubley, G.J.; Stack, E.C.; Signoretti, S.; Walsh, M.; et al. Neoadjuvant dose-dense methotrexate, vinblastine, doxorubicin, and cisplatin with pegfilgrastim support in muscle-invasive urothelial cancer: Pathologic, radiologic, and biomarker correlates. J. Clin. Oncol. Off. J. Am. Soc. Clin. Oncol. 2014, 32, 1889-1894. [CrossRef] [PubMed]

14. Plimack, E.R.; Hoffman-Censits, J.H.; Viterbo, R.; Trabulsi, E.J.; Ross, E.A.; Greenberg, R.E.; Chen, D.Y.; Lallas, C.D.; Wong, Y.N.; Lin, J.; et al. Accelerated methotrexate, vinblastine, doxorubicin, and cisplatin is safe, effective, and efficient neoadjuvant treatment for muscle-invasive bladder cancer: Results of a multicenter phase II study with molecular correlates of response and toxicity. J. Clin. Oncol. Off. J. Am. Soc. Clin. Oncol. 2014, 32, 1895-1901. [CrossRef]

15. von der Maase, H.; Sengelov, L.; Roberts, J.T.; Ricci, S.; Dogliotti, L.; Oliver, T.; Moore, M.J.; Zimmermann, A.; Arning, M. Longterm survival results of a randomized trial comparing gemcitabine plus cisplatin, with methotrexate, vinblastine, doxorubicin, plus cisplatin in patients with bladder cancer. J. Clin. Oncol. Off. J. Am. Soc. Clin. Oncol. 2005, 23, 4602-4608. [CrossRef]

16. Galsky, M.D.; Pal, S.K.; Chowdhury, S.; Harshman, L.C.; Crabb, S.J.; Wong, Y.N.; Yu, E.Y.; Powles, T.; Moshier, E.L.; Ladoire, S.; et al. Comparative effectiveness of gemcitabine plus cisplatin versus methotrexate, vinblastine, doxorubicin, plus cisplatin as neoadjuvant therapy for muscle-invasive bladder cancer. Cancer 2015, 121, 2586-2593. [CrossRef]

17. Lee, F.C.; Harris, W.; Cheng, H.H.; Shenoi, J.; Zhao, S.; Wang, J.; Champion, T.; Izard, J.; Gore, J.L.; Porter, M.; et al. Pathologic Response Rates of Gemcitabine/Cisplatin versus Methotrexate/Vinblastine/Adriamycin/Cisplatin Neoadjuvant Chemotherapy for Muscle Invasive Urothelial Bladder Cancer. Adv. Urol. 2013, 2013, 317190. [CrossRef] 
18. Dash, A.; Pettus, J.A.t.; Herr, H.W.; Bochner, B.H.; Dalbagni, G.; Donat, S.M.; Russo, P.; Boyle, M.G.; Milowsky, M.I.; Bajorin, D.F. A role for neoadjuvant gemcitabine plus cisplatin in muscle-invasive urothelial carcinoma of the bladder: A retrospective experience. Cancer 2008, 113, 2471-2477. [CrossRef]

19. Yuh, B.E.; Ruel, N.; Wilson, T.G.; Vogelzang, N.; Pal, S.K. Pooled analysis of clinical outcomes with neoadjuvant cisplatin and gemcitabine chemotherapy for muscle invasive bladder cancer. J. Urol. 2013, 189, 1682-1686. [CrossRef] [PubMed]

20. Iyer, G.; Tully, C.M.; Zabor, E.C.; Bochner, B.H.; Dalbagni, G.; Herr, H.W.; Donat, S.M.; Russo, P.; Ostrovnaya, I.; Regazzi, A.M.; et al. Neoadjuvant Gemcitabine-Cisplatin Plus Radical Cystectomy-Pelvic Lymph Node Dissection for Muscle-invasive Bladder Cancer: A 12-year Experience. Clin. Genitourin. Cancer 2020, 18, 387-394. [CrossRef] [PubMed]

21. Pfister, C.; Gravis, G.; Fléchon, A.; Soulié, M.; Guy, L.; Laguerre, B.; Mottet, N.; Joly, F.; Allory, Y.; Harter, V.; et al. Randomized Phase III Trial of Dose-dense Methotrexate, Vinblastine, Doxorubicin, and Cisplatin, or Gemcitabine and Cisplatin as Perioperative Chemotherapy for Patients with Muscle-invasive Bladder Cancer. Analysis of the GETUG/AFU V05 VESPER Trial Secondary Endpoints: Chemotherapy Toxicity and Pathological Responses. Eur. Urol. 2021, 79, 214-221.

22. Sternberg, C.N.; Skoneczna, I.; Kerst, J.M.; Albers, P.; Fossa, S.D.; Agerbaek, M.; Dumez, H.; de Santis, M.; Theodore, C.; Leahy, M.G.; et al. Immediate versus deferred chemotherapy after radical cystectomy in patients with pT3-pT4 or N+ M0 urothelial carcinoma of the bladder (EORTC 30994): An intergroup, open-label, randomised phase 3 trial. Lancet Oncol. 2015, $16,76-86$. [CrossRef]

23. Cognetti, F.; Ruggeri, E.M.; Felici, A.; Gallucci, M.; Muto, G.; Pollera, C.F.; Massidda, B.; Rubagotti, A.; Giannarelli, D.; Boccardo, F. Adjuvant chemotherapy with cisplatin and gemcitabine versus chemotherapy at relapse in patients with muscle-invasive bladder cancer submitted to radical cystectomy: An Italian, multicenter, randomized phase III trial. Ann. Oncol. Off. J. Eur. Soc. Med. Oncol. 2012, 23, 695-700. [CrossRef] [PubMed]

24. Paz-Ares, L.G.; Solsona, E.; Esteban, E.; Saez, A.; Gonzalez-Larriba, J.; Anton, A.; Hevia, M.; Rosa, F.d.l.; Guillem, V.; Bellmunt, J. Randomized phase III trial comparing adjuvant paclitaxel/gemcitabine/cisplatin (PGC) to observation in patients with resected invasive bladder cancer: Results of the Spanish Oncology Genitourinary Group (SOGUG) 99/01 study. J. Clin. Oncol. 2010, 28, LBA4518. [CrossRef]

25. Stadler, W.M.; Lerner, S.P.; Groshen, S.; Stein, J.P.; Shi, S.R.; Raghavan, D.; Esrig, D.; Steinberg, G.; Wood, D.; Klotz, L.; et al. Phase III study of molecularly targeted adjuvant therapy in locally advanced urothelial cancer of the bladder based on p53 status. J. Clin. Oncol. Off. J. Am. Soc. Clin. Oncol. 2011, 29, 3443-3449. [CrossRef] [PubMed]

26. Lehmann, J.; Franzaring, L.; Thüroff, J.; Wellek, S.; Stöckle, M. Complete long-term survival data from a trial of adjuvant chemotherapy vs control after radical cystectomy for locally advanced bladder cancer. BJU Int. 2006, 97, 42-47. [CrossRef] [PubMed]

27. Leow, J.J.; Martin-Doyle, W.; Rajagopal, P.S.; Patel, C.G.; Anderson, E.M.; Rothman, A.T.; Cote, R.J.; Urun, Y.; Chang, S.L.; Choueiri, T.K.; et al. Adjuvant chemotherapy for invasive bladder cancer: A 2013 updated systematic review and meta-analysis of randomized trials. Eur. Urol. 2014, 66, 42-54. [CrossRef]

28. Powles, T.; Duran, I.; van der Heijden, M.S.; Loriot, Y.; Vogelzang, N.J.; De Giorgi, U.; Oudard, S.; Retz, M.M.; Castellano, D.; Bamias, A.; et al. Atezolizumab versus chemotherapy in patients with platinum-treated locally advanced or metastatic urothelial carcinoma (IMvigor211): A multicentre, open-label, phase 3 randomised controlled trial. Lancet 2018, 391, 748-757. [CrossRef]

29. Patel, M.R.; Ellerton, J.; Infante, J.R.; Agrawal, M.; Gordon, M.; Aljumaily, R.; Britten, C.D.; Dirix, L.; Lee, K.W.; Taylor, M.; et al. Avelumab in metastatic urothelial carcinoma after platinum failure (JAVELIN Solid Tumor): Pooled results from two expansion cohorts of an open-label, phase 1 trial. Lancet Oncol. 2018, 19, 51-64. [CrossRef]

30. Sharma, P.; Retz, M.; Siefker-Radtke, A.; Baron, A.; Necchi, A.; Bedke, J.; Plimack, E.R.; Vaena, D.; Grimm, M.O.; Bracarda, S.; et al. Nivolumab in metastatic urothelial carcinoma after platinum therapy (CheckMate 275): A multicentre, single-arm, phase 2 trial. Lancet Oncol. 2017, 18, 312-322. [CrossRef]

31. Bellmunt, J.; de Wit, R.; Vaughn, D.J.; Fradet, Y.; Lee, J.L.; Fong, L.; Vogelzang, N.J.; Climent, M.A.; Petrylak, D.P.; Choueiri, T.K.; et al. Pembrolizumab as Second-Line Therapy for Advanced Urothelial Carcinoma. N. Engl. J. Med. 2017, 376, $1015-1026$. [CrossRef]

32. Fradet, Y.; Bellmunt, J.; Vaughn, D.J.; Lee, J.L.; Fong, L.; Vogelzang, N.J.; Climent, M.A.; Petrylak, D.P.; Choueiri, T.K.; Necchi, A.; et al. Randomized phase III KEYNOTE-045 trial of pembrolizumab versus paclitaxel, docetaxel, or vinflunine in recurrent advanced urothelial cancer: Results of $>2$ years of follow-up. Ann. Oncol. Off. J. Eur. Soc. Med. Oncol. 2019, 30, 970-976. [CrossRef]

33. Balar, A.V.; Castellano, D.; O’Donnell, P.H.; Grivas, P.; Vuky, J.; Powles, T.; Plimack, E.R.; Hahn, N.M.; de Wit, R.; Pang, L.; et al First-line pembrolizumab in cisplatin-ineligible patients with locally advanced and unresectable or metastatic urothelial cancer (KEYNOTE-052): A multicentre, single-arm, phase 2 study. Lancet Oncol. 2017, 18, 1483-1492. [CrossRef]

34. Powles, T.; O’Donnell, P.H.; Massard, C.; Arkenau, H.T.; Friedlander, T.W.; Hoimes, C.J.; Lee, J.L.; Ong, M.; Sridhar, S.S.; Vogelzang, N.J.; et al. Efficacy and Safety of Durvalumab in Locally Advanced or Metastatic Urothelial Carcinoma: Updated Results From a Phase 1/2 Open-label Study. JAMA Oncol. 2017, 3, e172411. [CrossRef]

35. Balar, A.V.; Galsky, M.D.; Rosenberg, J.E.; Powles, T.; Petrylak, D.P.; Bellmunt, J.; Loriot, Y.; Necchi, A.; Hoffman-Censits, J.; Perez-Gracia, J.L.; et al. Atezolizumab as first-line treatment in cisplatin-ineligible patients with locally advanced and metastatic urothelial carcinoma: A single-arm, multicentre, phase 2 trial. Lancet 2017, 389, 67-76. [CrossRef] 
36. Vuky, J.; Balar, A.V.; Castellano, D.; O’Donnell, P.H.; Grivas, P.; Bellmunt, J.; Powles, T.; Bajorin, D.; Hahn, N.M.; Savage, M.J.; et al. Long-Term Outcomes in KEYNOTE-052: Phase II Study Investigating First-Line Pembrolizumab in Cisplatin-Ineligible Patients With Locally Advanced or Metastatic Urothelial Cancer. J. Clin. Oncol. Off. J. Am. Soc. Clin. Oncol. 2020, 38, 2658-2666. [CrossRef] [PubMed]

37. Galsky, M.D.; Saci, A.; Szabo, P.M.; Han, G.C.; Grossfeld, G.; Collette, S.; Siefker-Radtke, A.; Necchi, A.; Sharma, P. Nivolumab in Patients with Advanced Platinum-resistant Urothelial Carcinoma: Efficacy, Safety, and Biomarker Analyses with Extended Follow-up from CheckMate 275. Clin. Cancer Res. 2020, 26, 5120. [CrossRef] [PubMed]

38. Necchi, A.; Anichini, A.; Raggi, D.; Briganti, A.; Massa, S.; Luciano, R.; Colecchia, M.; Giannatempo, P.; Mortarini, R.; Bianchi, M.; et al. Pembrolizumab as Neoadjuvant Therapy Before Radical Cystectomy in Patients With Muscle-Invasive Urothelial Bladder Carcinoma (PURE-01): An Open-Label, Single-Arm, Phase II Study. J. Clin. Oncol. Off. J. Am. Soc. Clin. Oncol. 2018, Jco1801148. [CrossRef] [PubMed]

39. Powles, T.; Rodriguez-Vida, A.; Duran, I.; Crabb, S.J.; Heijden, M.S.V.D.; Pous, A.F.; Gravis, G.; Herranz, U.A.; Protheroe, A.; Ravaud, A.; et al. A phase II study investigating the safety and efficacy of neoadjuvant atezolizumab in muscle invasive bladder cancer (ABACUS). J. Clin. Oncol. 2018, 36, 4506. [CrossRef]

40. Briganti, A.; Gandaglia, G.; Scuderi, S.; Gallina, A.; Colombo, R.; Fossati, N.; Barletta, F.; Pellegrino, A.; Nocera, L.; Montorsi, F.; et al. Surgical Safety of Radical Cystectomy and Pelvic Lymph Node Dissection Following Neoadjuvant Pembrolizumab in Patients with Bladder Cancer: Prospective Assessment of Perioperative Outcomes from the PURE-01 Trial. Eur. Urol. 2020, 77, 576-580. [CrossRef] [PubMed]

41. Bandini, M.; Gibb, E.A.; Gallina, A.; Raggi, D.; Marandino, L.; Bianchi, M.; Ross, J.S.; Colecchia, M.; Gandaglia, G.; Fossati, N.; et al. Does the administration of preoperative pembrolizumab lead to sustained remission post-cystectomy? First survival outcomes from the PURE-01 study. Ann. Oncol. 2020, 31, 1755-1763. [CrossRef]

42. Powles, T.; Kockx, M.; Rodriguez-Vida, A.; Duran, I.; Crabb, S.J.; Van Der Heijden, M.S.; Szabados, B.; Pous, A.F.; Gravis, G.; Herranz, U.A.; et al. Clinical efficacy and biomarker analysis of neoadjuvant atezolizumab in operable urothelial carcinoma in the ABACUS trial. Nat. Med. 2019, 25, 1706-1714. [CrossRef]

43. Melero, I.; Berman, D.M.; Aznar, M.A.; Korman, A.J.; Perez Gracia, J.L.; Haanen, J. Evolving synergistic combinations of targeted immunotherapies to combat cancer. Nat. Rev. Cancer 2015, 15, 457-472. [CrossRef] [PubMed]

44. Beer, T.M.; Kwon, E.D.; Drake, C.G.; Fizazi, K.; Logothetis, C.; Gravis, G.; Ganju, V.; Polikoff, J.; Saad, F.; Humanski, P.; et al. Randomized, Double-Blind, Phase III Trial of Ipilimumab Versus Placebo in Asymptomatic or Minimally Symptomatic Patients With Metastatic Chemotherapy-Naive Castration-Resistant Prostate Cancer. J. Clin. Oncol. Off. J. Am. Soc. Clin. Oncol. 2017, 35, 40-47. [CrossRef] [PubMed]

45. Galon, J.; Bruni, D. Approaches to treat immune hot, altered and cold tumours with combination immunotherapies. Nat. Rev. Drug Discov. 2019, 18, 197-218. [CrossRef] [PubMed]

46. Warner, A.B.; Postow, M.A. Combination Controversies: Checkpoint Inhibition Alone or in Combination for the Treatment of Melanoma? Oncology (Williston Park) 2018, 32, 228-234. [PubMed]

47. Curran, M.A.; Montalvo, W.; Yagita, H.; Allison, J.P. PD-1 and CTLA-4 combination blockade expands infiltrating T cells and reduces regulatory $\mathrm{T}$ and myeloid cells within B16 melanoma tumors. Proc. Natl. Acad. Sci. USA 2010, 107, 4275-4280. [CrossRef]

48. Selby, M.J.; Engelhardt, J.J.; Johnston, R.J.; Lu, L.S.; Han, M.; Thudium, K.; Yao, D.; Quigley, M.; Valle, J.; Wang, C.; et al. Preclinical Development of Ipilimumab and Nivolumab Combination Immunotherapy: Mouse Tumor Models, In Vitro Functional Studies, and Cynomolgus Macaque Toxicology. PLOS ONE 2016, 11, e0161779.

49. Rotte, A. Combination of CTLA-4 and PD-1 blockers for treatment of cancer. J. Exp. Clin. Cancer Res. 2019, 38, 255. [CrossRef]

50. van Dijk, N.; Gil-Jimenez, A.; Silina, K.; Hendricksen, K.; Smit, L.A.; de Feijter, J.M.; van Montfoort, M.L.; van Rooijen, C.; Peters, D.; Broeks, A.; et al. Preoperative ipilimumab plus nivolumab in locoregionally advanced urothelial cancer: The NABUCCO trial. Nat. Med. 2020, 26, 1839-1844. [CrossRef]

51. Grande, E.; Guerrero, F.; Puente, J.; Galante, I.; Duran, I.; Dominguez, M.; Gordoa, T.A.; Burgos, J.; Font, A.; Pinto, A.; et al. DUTRENEO Trial: A randomized phase II trial of DUrvalumab and TREmelimumab versus chemotherapy as a NEOadjuvant approach to muscle-invasive urothelial bladder cancer (MIBC) patients (pts) prospectively selected by an interferon (INF)-gamma immune signature. J. Clin. Oncol. 2020, 38, 5012. [CrossRef]

52. Hayashi, H.; Nakagawa, K. Combination therapy with PD-1 or PD-L1 inhibitors for cancer. Int. J. Clin. Oncol. 2020, 25, 818-830. [CrossRef]

53. Salas-Benito, D.; Pérez-Gracia, J.L.; Ponz-Sarvisé, M.; Rodriguez-Ruiz, M.E.; Martínez-Forero, I.; Castañón, E.; López-Picazo, J.M.; Sanmamed, M.F.; Melero, I. Paradigms on Immunotherapy Combinations with Chemotherapy. Cancer Discov. 2021, 11, $1353-1367$. [CrossRef] [PubMed]

54. Galluzzi, L.; Humeau, J.; Buqué, A.; Zitvogel, L.; Kroemer, G. Immunostimulation with chemotherapy in the era of immune checkpoint inhibitors. Nat. Rev. Clin. Oncol. 2020, 17, 725-741. [CrossRef] [PubMed]

55. Gupta, S.; Sonpavde, G.; Weight, C.J.; McGregor, B.A.; Gupta, S.; Maughan, B.L.; Wei, X.X.; Gibb, E.; Thyagarajan, B.; Einstein, D.J.; et al. Results from BLASST-1 (Bladder Cancer Signal Seeking Trial) of nivolumab, gemcitabine, and cisplatin in muscle invasive bladder cancer (MIBC) undergoing cystectomy. J. Clin. Oncol. 2020, 38, 439. [CrossRef] 
56. Hoimes, C.J.; Adra, N.; Fleming, M.T.; Kaimakliotis, H.Z.; Picus, J.; Smith, Z.L.; Walling, R.; Trabulsi, E.J.; Hoffman-Censits, J.H.; Koch, M.O.; et al. Phase Ib/II neoadjuvant (N-) pembrolizumab (P) and chemotherapy for locally advanced urothelial cancer (laUC): Final results from the cisplatin (C)- eligible cohort of HCRN GU14-188. J. Clin. Oncol. 2020, 38, 5047. [CrossRef]

57. Kaimakliotis, H.Z.; Adra, N.; Kelly, W.K.; Trabulsi, E.J.; Lauer, R.C.; Picus, J.; Smith, Z.L.; Walling, R.; Masterson, T.A.; Calaway, A.C.; et al. Phase II neoadjuvant (N-) gemcitabine $(\mathrm{G})$ and pembrolizumab (P) for locally advanced urothelial cancer (laUC): Interim results from the cisplatin (C)-ineligible cohort of GU14-188. J. Clin. Oncol. 2020, 38, 5019. [CrossRef]

58. Birrer, M.J.; Moore, K.N.; Betella, I.; Bates, R.C. Antibody-Drug Conjugate-Based Therapeutics: State of the Science. J. Natl. Cancer Inst. 2019, 111, 538-549. [CrossRef] [PubMed]

59. Rosenberg, J.E.; O’Donnell, P.H.; Balar, A.V.; McGregor, B.A.; Heath, E.I.; Yu, E.Y.; Galsky, M.D.; Hahn, N.M.; Gartner, E.M.; Pinelli, J.M.; et al. Pivotal Trial of Enfortumab Vedotin in Urothelial Carcinoma After Platinum and Anti-Programmed Death 1/Programmed Death Ligand 1 Therapy. J. Clin. Oncol. Off. J. Am. Soc. Clin. Oncol. 2019, 37, 2592-2600. [CrossRef]

60. Challita-Eid, P.M.; Satpayev, D.; Yang, P.; An, Z.; Morrison, K.; Shostak, Y.; Raitano, A.; Nadell, R.; Liu, W.; Lortie, D.R.; et al. Enfortumab Vedotin Antibody-Drug Conjugate Targeting Nectin-4 Is a Highly Potent Therapeutic Agent in Multiple Preclinical Cancer Models. Cancer Res. 2016, 76, 3003-3013. [CrossRef]

61. Powles, T.; Rosenberg, J.E.; Sonpavde, G.; Loriot, Y.; Duran, I.; Lee, J.-L.; Matsubara, N.; Vulsteke, C.; Wu, C.; Campbell, M.S.; et al. Primary results of EV-301: A phase III trial of enfortumab vedotin versus chemotherapy in patients with previously treated locally advanced or metastatic urothelial carcinoma. J. Clin. Oncol. 2021, 39, 393. [CrossRef]

62. Trerotola, M.; Cantanelli, P.; Guerra, E.; Tripaldi, R.; Aloisi, A.L.; Bonasera, V.; Lattanzio, R.; de Lange, R.; Weidle, U.H.; Piantelli, M.; et al. Upregulation of Trop-2 quantitatively stimulates human cancer growth. Oncogene 2013, 32, 222-233. [CrossRef] [PubMed]

63. Avellini, C.; Licini, C.; Lazzarini, R.; Gesuita, R.; Guerra, E.; Tossetta, G.; Castellucci, C.; Giannubilo, S.R.; Procopio, A.; Alberti, S.; et al. The trophoblast cell surface antigen 2 and miR-125b axis in urothelial bladder cancer. Oncotarget 2017, 8, 58642-58653. [CrossRef] [PubMed]

64. Tagawa, S.T.; Faltas, B.M.; Lam, E.T.; Saylor, P.J.; Bardia, A.; Hajdenberg, J.; Morgans, A.K.; Lim, E.A.; Kalinsky, K.; Simpson, P.S.; et al. Sacituzumab govitecan (IMMU-132) in patients with previously treated metastatic urothelial cancer (mUC): Results from a phase I/II study. J. Clin. Oncol. 2019, 37, 354. [CrossRef]

65. Loriot, Y.; Balar, A.V.; Petrylak, D.P.; Tagawa, S.T.; Rezazadeh, A.; Fléchon, A.; Jain, R.; Agarwal, N.; Bupathi, M.; Barthélémy, P.; et al. LBA24 TROPHY-U-01 cohort 1 final results: A phase II study of sacituzumab govitecan (SG) in metastatic urothelial cancer (mUC) that has progressed after platinum (PLT) and checkpoint inhibitors (CPI). Ann. Oncol. 2020, 31, S1156. [CrossRef]

66. Grivas, P.; Sternberg, C.N.; Agarwal, N.; Petrylak, D.P.; Tagawa, S.T.; Hong, Q.; Gladden, A.; Kanwal, C.; Goswami, T.; Loriot, Y. 796TiP TROPHY-U-01 Cohort 3: Sacituzumab govitecan (SG) and pembrolizumab (pembro) in patients (pts) with progression or recurrence of metastatic urothelial cancer (mUC) after platinum (PLT)-based therapy. Ann. Oncol. 2020, 31, S604-S605. [CrossRef]

67. Necchi, A.; Raggi, D.; Bandini, M.; Gallina, A.; Capitanio, U.; Gandaglia, G.; Cucchiara, V.; Fossati, N.; Cobelli, F.D.; Salonia, A.; et al. SURE: An open label, sequential-arm, phase II study of neoadjuvant sacituzumab govitecan (SG), and SG plus pembrolizumab (pembro) before radical cystectomy, for patients with muscle-invasive bladder cancer (MIBC) who cannot receive or refuse cisplatin-based chemotherapy. J. Clin. Oncol. 2021, 39, TPS506.

68. Rodriguez-Moreno, J.F.; Velasco, G.d.; Fernandez, I.B.; Alvarez-Fernandez, C.; Fernandez, R.; Vazquez-Estevez, S.; Virizuela, J.A.; Gajate, P.; Font, A.; Lainez, N.; et al. Impact of the combination of durvalumab (MEDI4736) plus olaparib (AZD2281) administered prior to surgery in the molecular profile of resectable urothelial bladder cancer: NEODURVARIB Trial. J. Clin. Oncol. 2020, 38, 542. [CrossRef]

69. Milowsky, M.; Davis, N.; Fung, C.; Johnson, S.; Langenstroer, P.; Jacobsohn, K.; Bylow, K.; Kilari, D. 801TiP A phase II study of cabozantinib in combination with atezolizumab as neoadjuvant treatment for muscle-invasive bladder cancer (ABATE). Ann. Oncol. 2020, 31, S607. [CrossRef]

70. Sethakorn, N.; O'Donnell, P.H. Spectrum of genomic alterations in FGFR3: Current appraisal of the potential role of FGFR3 in advanced urothelial carcinoma. BJU Int. 2016, 118, 681-691. [CrossRef]

71. Loriot, Y.; Necchi, A.; Park, S.H.; Garcia-Donas, J.; Huddart, R.; Burgess, E.; Fleming, M.; Rezazadeh, A.; Mellado, B.; Varlamov, S.; et al. Erdafitinib in Locally Advanced or Metastatic Urothelial Carcinoma. N. Engl. J. Med. 2019, 381, 338-348. [CrossRef]

72. Park, I.; Lee, J.L. Systemic treatment for advanced urothelial cancer: An update on recent clinical trials and current treatment options. Korean J. Intern. Med. 2020, 35, 834-853. [CrossRef]

73. Alkassis, M.; Sarkis, J.; Tayeh, G.A.; Kourie, H.R.; Nemer, E. Immunotherapy in neoadjuvant setting in muscle-invasive bladder cancer, what's new? Immunotherapy 2021, 13, 459-463. [CrossRef] [PubMed]

74. Bellmunt, J.; Hussain, M.; Gschwend, J.E.; Albers, P.; Oudard, S.; Castellano, D.; Daneshmand, S.; Nishiyama, H.; Majchrowicz, M.; Degaonkar, V.; et al. Adjuvant atezolizumab versus observation in muscle-invasive urothelial carcinoma (IMvigor010): A multicentre, open-label, randomised, phase 3 trial. Lancet Oncol. 2021, 22, 525-537. [CrossRef]

75. Bajorin, D.F.; Witjes, J.A.; Gschwend, J.; Schenker, M.; Valderrama, B.P.; Tomita, Y.; Bamias, A.; Lebret, T.; Shariat, S.; Park, S.H.; et al. First results from the phase 3 CheckMate 274 trial of adjuvant nivolumab vs placebo in patients who underwent radical surgery for high-risk muscle-invasive urothelial carcinoma (MIUC). J. Clin. Oncol. 2021, 39, 391. [CrossRef] 
76. Apolo, A.B.; Rosenberg, J.E.; Kim, W.Y.; Chen, R.C.; Sonpavde, G.; Srinivas, S.; Mortazavi, A.; Watt, C.; Mallek, M.; Graap, K.; et al. Alliance A031501: Phase III randomized adjuvant study of MK-3475 (pembrolizumab) in muscle-invasive and locally advanced urothelial carcinoma (MIBC) (AMBASSADOR) versus observation. J. Clin. Oncol. 2019, 37, TPS504. [CrossRef]

77. Steenbruggen, T.G.; van Ramshorst, M.S.; Kok, M.; Linn, S.C.; Smorenburg, C.H.; Sonke, G.S. Neoadjuvant Therapy for Breast Cancer: Established Concepts and Emerging Strategies. Drugs 2017, 77, 1313-1336. [CrossRef] [PubMed]

78. Kim, I.H.; Lee, H.J. Perioperative immunotherapy for muscle-invasive bladder cancer. Transl. Androl. Urol. 2020, 9, $2976-2985$. [CrossRef] [PubMed]

79. Shariat, S.F.; Tokunaga, H.; Zhou, J.; Kim, J.; Ayala, G.E.; Benedict, W.F.; Lerner, S.P. p53, p21, pRB, and p16 expression predict clinical outcome in cystectomy with bladder cancer. J. Clin. Oncol. Off. J. Am. Soc. Clin. Oncol. 2004, 22, 1014-1024. [CrossRef]

80. Shariat, S.F.; Lotan, Y.; Karakiewicz, P.I.; Ashfaq, R.; Isbarn, H.; Fradet, Y.; Bastian, P.J.; Nielsen, M.E.; Capitanio, U.; Jeldres, C.; et al. p53 predictive value for pT1-2 N0 disease at radical cystectomy. J. Urol. 2009, 182, 907-913. [CrossRef]

81. Comprehensive molecular characterization of urothelial bladder carcinoma. Nature 2014, 507, 315-322. [CrossRef]

82. Rosenberg, J.E.; Hoffman-Censits, J.; Powles, T.; van der Heijden, M.S.; Balar, A.V.; Necchi, A.; Dawson, N.; O'Donnell, P.H.; Balmanoukian, A.; Loriot, Y.; et al. Atezolizumab in patients with locally advanced and metastatic urothelial carcinoma who have progressed following treatment with platinum-based chemotherapy: A single-arm, multicentre, phase 2 trial. Lancet 2016, 387, 1909-1920. [CrossRef]

83. Sharma, P.; Callahan, M.K.; Bono, P.; Kim, J.; Spiliopoulou, P.; Calvo, E.; Pillai, R.N.; Ott, P.A.; de Braud, F.; Morse, M.; et al. Nivolumab monotherapy in recurrent metastatic urothelial carcinoma (CheckMate 032): A multicentre, open-label, two-stage, multi-arm, phase 1/2 trial. Lancet Oncol. 2016, 17, 1590-1598. [CrossRef]

84. Garon, E.B.; Rizvi, N.A.; Hui, R.; Leighl, N.; Balmanoukian, A.S.; Eder, J.P.; Patnaik, A.; Aggarwal, C.; Gubens, M.; Horn, L.; et al. Pembrolizumab for the treatment of non-small-cell lung cancer. N. Engl. J. Med. 2015, 372, 2018-2028. [CrossRef] [PubMed]

85. Colli, L.M.; Machiela, M.J.; Myers, T.A.; Jessop, L.; Yu, K.; Chanock, S.J. Burden of Nonsynonymous Mutations among TCGA Cancers and Candidate Immune Checkpoint Inhibitor Responses. Cancer Res. 2016, 76, 3767-3772. [CrossRef] [PubMed]

86. Le, D.T.; Durham, J.N.; Smith, K.N.; Wang, H.; Bartlett, B.R.; Aulakh, L.K.; Lu, S.; Kemberling, H.; Wilt, C.; Luber, B.S.; et al. Mismatch repair deficiency predicts response of solid tumors to PD-1 blockade. Science 2017, 357, 409-413. [CrossRef] [PubMed]

87. McGranahan, N.; Furness, A.J.; Rosenthal, R.; Ramskov, S.; Lyngaa, R.; Saini, S.K.; Jamal-Hanjani, M.; Wilson, G.A.; Birkbak, N.J.; Hiley, C.T.; et al. Clonal neoantigens elicit T cell immunoreactivity and sensitivity to immune checkpoint blockade. Science 2016, 351, 1463-1469. [CrossRef]

88. Powles, T.B.; Assaf, Z.J.; Davarpanah, N.; Hussain, M.; Oudard, S.; Gschwend, J.E.; Albers, P.; Castellano, D.; Nishiyama, H.; Daneshmand, S.; et al. $1 \mathrm{O}$ Clinical outcomes in post-operative ctDNA-positive muscle-invasive urothelial carcinoma (MIUC) patients after atezolizumab adjuvant therapy. Ann. Oncol. 2020, 31, S1417. [CrossRef] 